\title{
Análise clínica e morfológica da conjuntivite alérgica induzida por ovalbumina e tratada com chalcona em cobaias ${ }^{1}$
}

\author{
Rosemary Jorge de Mendonça Albuquerque ${ }^{2}$, Lusmar Veras Rodrigues ${ }^{3}$, Glauce Socorro de Barros Viana ${ }^{4}$
}

\begin{abstract}
Mendonça ARJ, Rodrigues L, Viana GSB. Análise clínica e morfológica da conjuntivite alérgica induzida por ovalbumina e tratada com chalcona, em cobaias. Acta Cir Bras [serial online] 2004 Jan-Fev;19(1). Disponível em URL: http://www.scielo.br/acb.

RESUMO - Objetivo: Verificar, do ponto de vista clínico e morfológico, o efeito da chalcona na conjuntivite alérgica induzida por ovalbumina em cobaias. Métodos: Utilizaram-se 54 cobaias, albinos, machos pesando aproximadamente $400 \mathrm{~g}$. Os animais foram sensibilizados por injeção intraperitoneal de ovalbumina suspensa em solução adjuvante completa de Freund. Posteriormente, a conjuntivite alérgica foi induzida por instilação de ovalbumina no saco conjuntival do olho direito. Os animais foram distribuídos em 3 grupos, conforme o tratamento proposto: chalcona, corticóide e salina. A avaliação clínica foi realizada com 5, 10 e 40 min, 7 e 24 h da indução e diariamente até o dia 7 da indução. A avaliação morfológica consistiu em avaliar edema, necrose, vascularização e exocitose nos dias 1, 3 e 7 da indução. Resultados: Em todos os grupos a resposta inflamatória foi mais intensa $24 \mathrm{~h}$ após a indução. No grupo chalcona evidenciou-se menos sinais inflamatórios que no grupo salina. O grupo corticóide apresentou menos sinais inflamatórios quando comparados aos grupos chalcona e controle. À análise morfológica evidenciou-se que os grupos chalcona e corticóide apresentaram efeitos terapêuticos semelhantes. Conclusão: A chalcona teve efeito terapêutico na conjuntivite alérgica induzida por ovalbumina.
\end{abstract}

DESCRITORES - Conjuntivite alérgica. Ovalbumina. Chalcona. Aroeira-do-sertão. Cobaias.

\section{Introdução}

A alergia ocular caracteriza-se por uma reação de hipersensibilidade de intensidade variável, aguda ou crônica, recorrente, que pode acometer pálpebras, conjuntiva e córnea, podendo levar a um comprometimento visual importante ${ }^{(1)}$.

A ceratoconjuntivite vernal é uma doença inflamatória crônica de etiologia alérgica, caracterizada por acentuado prurido, blefaroespasmo, fotofobia e secreção mucosa. A hipertrofia papilar é o achado mais freqüente localizado principalmente na conjuntiva tarsal superior podendo ainda estar presente no limbo. Pontos de HornerTrantas (acúmulo de eosinófilos) podem também ser encontrados no limbo. A córnea pode apresentar ceratite punctata localizada ou difusa e úlcera em escudo. A patogenia permanece desconhecida, mas parece ser mediada por anticorpos IgE, IgG e pela imunidade celular ${ }^{(2)}$.

Com o objetivo de estudar efeitos fisiopatológicos e terapêuticos da conjuntivite alérgica, foram desenvolvidos vários modelos experimentais de alergia ocular que mostraram alterações semelhantes às encontradas na conjuntivite vernal em humanos, e aqueles que utilizam a ovalbumina como sensibilizante em cobaias, são os mais usados ${ }^{(3,4)}$.

Diversos pesquisadores estudaram os efeitos de antihistamínicos, esteróides, cromoglicato de sódio, lodoxamida, $\mathrm{N}$ acetil aspartilglutamato de sódio, benzodiazepínicos, nedocromil, indome- tacina , ciclosporina e aspirina ${ }^{(5-11)}$. Além disso, várias pesquisas demonstraram que a espécie Myracrodruon urundeuva da família Anacardiaceae, (aroeira-dosertão), planta nativa da caatinga nordestina, tem efeito antiinflamatório, cicatrizante, antiulcerogênico, anti-histamínico, antibradicinina e analgésico no tratamento de diversas afecções ${ }^{(12-13)}$. Recentemente duas frações foram isoladas da entrecasca da planta por meio de fracionamento químico: uma fração rica em tanino e outra rica em chalcona ${ }^{(12-13)}$. Esta última é objeto de estudo do presente trabalho.

Apesar do uso de diversas substâncias no tratamento da ceratoconjuntivite vernal, a aroeira-do-sertão é de fácil aquisição e baixo custo, portanto decidiu-se avaliar os efeitos da chalcona na alergia ocular

1. Trabalho realizado no Laboratório de Neurofarmacologia do Departamento de Fisiologia e Farmacologia da Universidade Federal do Ceará, Programa de Pós-Graduação stricto sensu em Cirurgia, Faculdade de Medicina, Departamento de Cirurgia da Universidade Federal do Ceará (UFC), Fortaleza-CE.

2. Mestranda em Cirurgia do Departamento de Cirurgia, UFC, Fortaleza-CE.

3. Livre-Docente do Departamento de Cirurgia, Faculdade de Medicina, UFC, Fortaleza-CE.

4. Professora Titular do Departamento de Fisiologia e Farmacologia, UFC, Fortaleza-CE. 
na tentativa de buscar formas alternativas de tratamento para essa afecção.

\section{Métodos}

A pesquisa foi realizada de acordo com as Normas Internacionais para a Pesquisa Biomédica em Animais (1990) conforme a Lei Federal $\mathrm{n}^{\mathbf{0}}$ 6.638, de 08 de maio de $1979^{(14)}$.

Foram utilizadas 54 cobaias (Cavius porcellos), machos, com peso médio de $400 \mathrm{~g}$, procedentes do Biotério do Centro de Hematologia e Hemoterapia do Ceará (Hemoce).

Os animais foram sensibilizados com duas injeções intraperitoneais de $10 \mu \mathrm{g}$ de ovalbumina diluída em $0,5 \mathrm{ml}$ de solução salina a $0,9 \%$ e emulsificada com $0,5 \mathrm{ml}$ de solução adjuvante de Freund. A primeira sensibilização ocorreu no dia zero e a segunda no dia sete do experimento.

No dia 24 do experimento, que correspondia a 24 dias após a primeira sensibilização, foi realizada a indução da conjuntivite alérgica com a instilação no saco conjuntival do olho direito de cada animal com $5 \mathrm{mg}$ de ovalbumina diluída em $10 \mu \mathrm{l}$ de solução salina a $0,9 \%$. No olho esquerdo, foram instilados $10 \mu \mathrm{l}$ de solução salina a $0,9 \%$.

Os animais foram distribuídos ao acaso em três grupos com 18 animais cada um, conforme o tratamento proposto: grupo chalcona (animais tratados com chalcona; grupo corticóide (animais tratados com acetato de fluormetolona) e grupo salina (animais tratados com solução salina a $0,9 \%$ ). Os animais foram tratados, observados diariamente e avaliados do ponto de vista clínico e morfológico nos dias 1 , 3 e 7 a partir da indução da conjuntivite.

Após $24 \mathrm{~h}$ da indução da conjuntivite alérgica foi iniciado o tratamento. Os animais foram tratados até dia 7 da indução e avaliados a cada 24 horas. O grupo chalcona foi tratado com a instilação ocular de $0,5 \mathrm{mg}$ de chalcona três vezes ao dia. $\mathrm{O}$ volume utilizado foi de $50 \mu \mathrm{l}$ de uma solução de $10 \mathrm{mg}$ de chalcona por $1 \mathrm{ml}$ de solução salina a $0,9 \%$. O grupo corticóide foi tratado com a instilação ocular de $50 \mu \mathrm{l}$ correspondente a $0,05 \mathrm{mg}$ de acetato de fluormetolona $0,1 \%$ suspensão oftálmica administrada três vezes ao dia até dia $7 \mathrm{da}$

indução. O grupo salina foi tratado com a instilação de $50 \mu \mathrm{l}$ de salina $0,9 \%$ três vezes ao dia até dia 7 da indução. Nos três grupos, o tratamento citado foi instituído no olho direito de cada animal e no olho esquerdo foram instilados $50 \mu \mathrm{l}$ de solução salina a $0,9 \%$ no saco conjuntival.

\section{Evolução clínica}

\begin{tabular}{cl}
\hline Grau & \multicolumn{1}{c}{ Sinais } \\
\hline 0 & Ausência de reação \\
1 & Hiperemia conjuntival \\
2 & Acentuada hiperemia conjuntival e quemose \\
3 & $\begin{array}{l}\text { Acentuada hiperemia conjuntival, quemose e quemose conjuntival } \\
\text { cobrindo a córnea }\end{array}$ \\
4 & $\begin{array}{l}\text { Acentuada hiperemia conjuntival, quemose conjuntival } \\
\text { envolvendo córnea e fluído lacrimal turvo } \\
5\end{array}$ \\
& $\begin{array}{l}\text { Acentuada hiperemia conjuntival, quemose conjuntival envol- } \\
\text { vendo a córnea, fluído lacrimal turvo e descarga purulenta na } \\
\text { superfície ocular }\end{array}$ \\
\hline
\end{tabular}

QUADRO 1 - Escores usados na evolução clínica dos animais, conforme Sompolinsky (1992). Os escores foram acrescidos de 0,5 por um ou mais dos sintomas: pronunciada hiperemia palpebral; opacificação ou úlcera córnea. O valor máximo de escores foi limitado a 5 pontos.

\section{Avaliação morfológica}

Foi realizada a enucleação e os olhos foram fixados em solução de formalina à $10 \%$ e encaminhados para a rotina de preparo de lâminas no Laboratório de Patologia do Departamento de Patologia e Medicina Legal da Faculdade de Medicina da Universidade Federal do Ceará.

Os cortes foram realizados na espessura de 4 micrômetros, no sentido longitudinal, sendo dispostos três cortes por lâmina e submetidos à coloração pela hematoxilinaeosina e azul de toluidina. Foram preparadas seis lâminas por cada olho de cada animal. A leitura foi feita em microscópio óptico com magnitude de 40, 100 e $400 \mathrm{Xe}$ registrada a presença de exocitose, edema, vasos e necrose.

A presença de edema, vasos, necrose e exocitose foi avaliada utilizando-se uma escala de escores de 0-3 (0- ausência do parâmetro; 1 - leve; 2- moderado; 3 acentuado) ${ }^{(3,15)}$.

\section{Análise estatística}

Para a análise estatística dos resultados os diferentes grupos foram avaliados usando-se a análise de variância por postos de Kruskal-Wallis com o objetivo de comparar os três grupos nos três períodos estudados. Quando mostrou

\section{Avaliação clínica}

As alterações oculares foram observadas com 5,10 e 40 min, 7 e 24 h e diariamente até o dia 7 da indução. Os critérios adotados para a avaliação clinica tiveram como base o escore descrito por Sompolinsky (1992) ${ }^{(3)}$ conforme consta no Quadro 1. diferença significante, a análise foi complementada com o teste de Wilcoxon para comparação entre dois grupos. Em todos os testes fixou-se em 0,05 ou $5 \%$ o nível para rejeição da hipótese de nulidade.

\section{Resultados}

Os achados da avaliação clínica estão discriminados nas tabelas e gráficos abaixo e mostraram que em todos os grupos as alterações clínicas foram mais acentuadas com $24 \mathrm{~h}$ da indução da conjuntivite alérgica. No dia 3 da indução, no grupo chalcona evidenciaram-se menos sinais inflamatórios que no grupo salina. O grupo corticóide apresentou menos sinais inflamatórios quando comparado aos grupos chalcona e controle. No dia 7 da indução, observouse involução clínica do processo inflamatório em todos os grupos tratados.

À análise morfológica observou-se que os três grupos não apresentaram diferenças significantes antes do tratamento. À análise morfológica da córnea do OD evidenciou-se que no terceiro dia da indução, os grupos chalconas e corticóide apresentaram exocitose significantemente menor que o controle, sem ter havido diferenças significantes entre si. Em relação ao edema, necrose e vascularização não foram evidenciadas alterações significantes entre os grupos tratados (Tabelas 4 e 5). 
TABELA 1 - Média \pm E. P. M. dos escores da avaliação clínica nas primeiras 24 h da indução da conjuntivite alérgica em cobaias e distribuídas nos grupos chalcona, corticóide e salina

\begin{tabular}{cccc}
\hline \multicolumn{4}{c}{$\begin{array}{c}\text { Escores de avaliação clínica } \\
\text { (Média } \pm \text { E. P. M.) }\end{array}$} \\
\hline Períodos & Chalcona & Corticóide & Salina \\
\hline 5 min & $0,67 \pm 0,21$ & $0,50 \pm 0,22$ & $0,83 \pm 0,17$ \\
$10 \mathrm{~min}$ & $1,67 \pm 0,21$ & $1,50 \pm 0,22$ & $1,50 \pm 0,34$ \\
$40 \mathrm{~min}$ & $2,25 \pm 0,25$ & $2,33 \pm 0,21$ & $2,42 \pm 0,20$ \\
$7 \mathrm{~h}$ & $3,17 \pm 0,17$ & $3,08 \pm 0,15$ & $3,25 \pm 0,11$ \\
$24 \mathrm{~h}$ & $4,92 \pm 0,08$ & $4,83 \pm 0,11$ & $4,92 \pm 0,08$ \\
\hline
\end{tabular}

Teste de Kruskal-Wallis

$$
\left(H_{\text {critico }}=5,71\right) H_{\text {calculado }}=0,62
$$

Período 24h

$$
A=C=S
$$

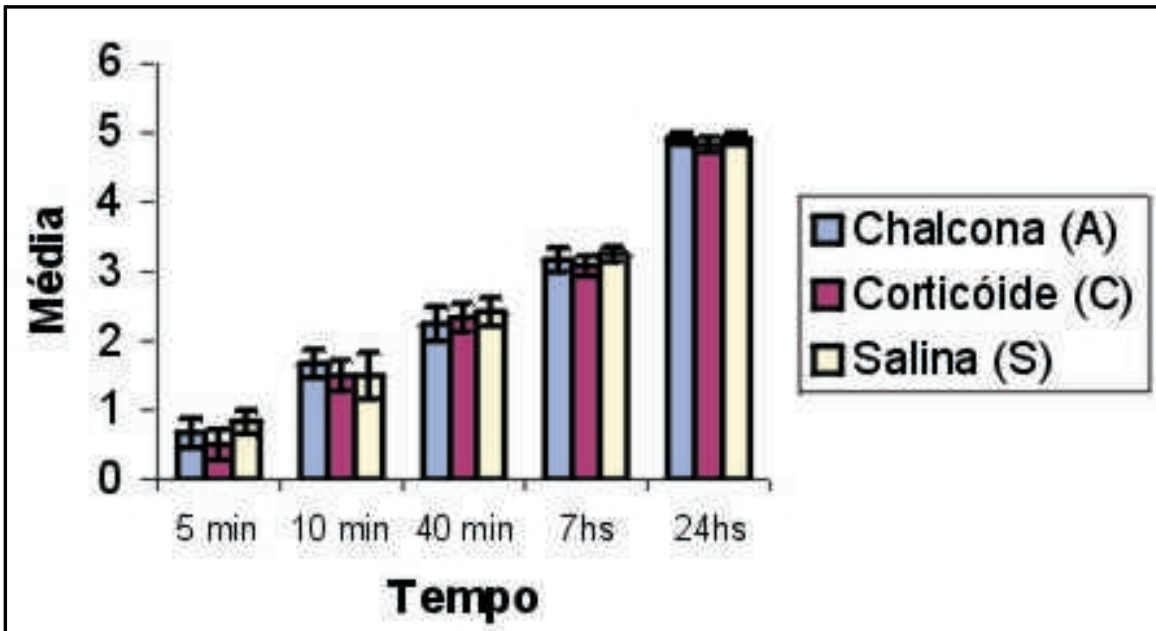

FIGURA 1 - Média \pm E. P. M. dos escores da avaliação clínica nas primeiras 24 hs da indução da conjuntivite alérgica em cobaias e distribuídas nos grupos chalcona, corticóide e salina.

TABELA 2 - Média \pm E. P. M. dos escores da avaliação clínica até o dia 3 da indução da conjuntivite alérgica em cobaias e tratada com chalcona, corticóide e salina

\begin{tabular}{cccc}
\hline & \multicolumn{3}{c}{ Média \pm E. P. M. dos escores } \\
\hline Períodos (dias) & Chalcona & Corticóide & Salina \\
\hline 1 & $4,75 \pm 0,11$ & $4,93 \pm 0,08$ & $4,64 \pm 0,10$ \\
2 & $4,50 \pm 0,13$ & $4,79 \pm 0,11$ & $4,79 \pm 0,11$ \\
3 & $4,17 \pm 0,17$ & $3,41 \pm 0,26$ & $4,64 \pm 0,19$ \\
\hline \multicolumn{4}{c}{ Teste de Kruskal-Wallis } \\
( $\left.\mathrm{H}_{\text {critico }}=5,71\right)$ & & \\
Período 3 & Teste de Wilcoxon & $\mathrm{C}<\mathrm{S}$ à $\mathrm{W}_{\text {calculado }}=22,5^{\star}$ \\
$\mathrm{H}_{\text {calculado }}=10,27^{*}$ & $\left(\mathrm{~W}_{\text {critico }}=28\right)$ & $\mathrm{A}<\mathrm{S}$ à $\mathrm{W}_{\text {calculado }}=26,5^{\star}$ \\
& & $\mathrm{C}<\mathrm{A}$ à $\mathrm{W}_{\text {calculado }}=27,0^{*}$
\end{tabular}

$\mathrm{p}<0,05$ entre os grupos tratados no dia 3. $\mathrm{C}<\mathrm{S} ; \mathrm{A}<\mathrm{S} ; \mathrm{C}<\mathrm{A}$
À análise morfológica da conjuntiva do OD observou-se que os grupos chalcona e corticóide apresentaram exocitose, edema, necrose e vascularização significantemente menor que o controle no período 3. No período 7, o grupo chalcona apresentou exocitose e edema significantemente menor que o controle. Não houve diferença significante entre os grupos corticóide e chalcona nos períodos estudados.

\section{Discussão}

O uso popular de Myracrodruon urundeuva (aroeira-do-sertão), como antiinflamatório, em diversas afecções e suas propriedades antiinflamatórias e antiulcerogênicas comprovadas ${ }^{(12-13)}$, estimularam o estudo de sua atividade, na alergia ocular. Para tanto, decidiu-se avaliar do ponto de vista clínico e morfológico, o efeito de uma fração rica em chalcona isolada da entrecasca da aroeira-do-sertão, na conjuntivite alérgica induzida por ovalbumina, em cobaias.

Diversos modelos experimentais foram reproduzidos para estudar reações de hipersensibilidade em conjuntiva de cobaias. A preferência pelo modelo de conjuntivite alérgica induzida por ovalbumina diluída em solução adjuvante de Freund em cobaias ocorreu por ser de fácil exeqüibilidade, ser reproduzido em $100 \%$ dos animais e induzir processo alérgico ocular agudo com alterações clínicas e morfológicas comprovadas ${ }^{(3,4)}$. A ovalbumina tem sido o antígeno frequentemente utilizado para a imunização de cobaias com ou sem solução adjuvante. Quando utilizada de maneira isolada em animais imunizados provocou uma reação inflamatória aguda a qual teve duração de poucas horas e não causou alterações histopatológicas importantes ${ }^{(5)}$. No entanto, no modelo reproduzido nesta pesquisa, utilizou-se a ovalbumina juntamente com solução adjuvante de Freund administrada por via intraperitoneal para provocar uma sensibilização nos animais e obter um modelo de hipersensibilidade celular ${ }^{(3,4)}$.

Os primeiros sinais de alergia apareceram com 5 minutos após a indução e consistiram de pronunciada hiperemia conjuntival. Aos 10 minutos surgiu a quemose que foi se acentuando e cobrindo toda a super- 


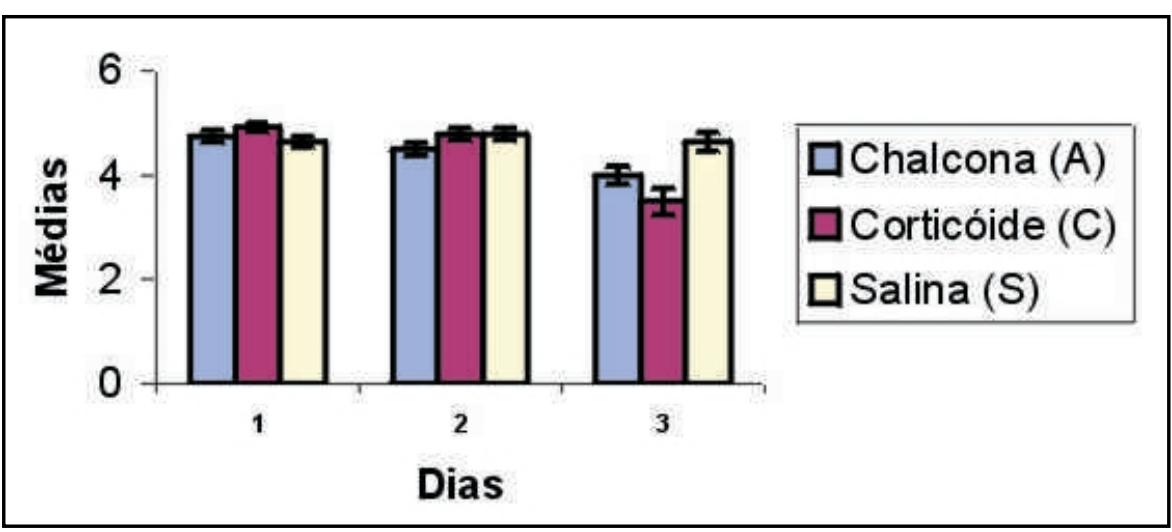

FIGURA 2 - Média \pm E. P. M. dos escores da avaliação clínica até o dia 3 da indução da conjuntivite alérgica em cobaias e tratada com chalcona, corticóide e salina.

TABELA 3 - Média \pm E. P. M. de escores da avaliação clínica observados até o dia 7 da indução da conjuntivite alérgica em cobaias e tratada com chalcona, corticóide e salina.

\begin{tabular}{cccc}
\hline \multicolumn{4}{c}{ Média \pm E.P.M. dos escores de avaliação clínica } \\
\hline Dias & Chalcona & Corticóide & Salina \\
\hline 1 & $4,83 \pm 0,11$ & $4,75 \pm 0,11$ & $4,75 \pm 0,11$ \\
2 & $3,92 \pm 0,24$ & $3,42 \pm 0,20$ & $3,92 \pm 0,24$ \\
3 & $2,25 \pm 0,17$ & $1,67 \pm 0,21$ & $2,75 \pm 0,17$ \\
4 & $1,08 \pm 0,08$ & $0,33 \pm 0,21$ & $1,33 \pm 0,21$ \\
5 & $0,50 \pm 0,22$ & $0,00 \pm 0,00$ & $1,00 \pm 0,26$ \\
6 & $0,00 \pm 0,00$ & $0,00 \pm 0,00$ & $0,00 \pm 0,00$ \\
7 & $0,00 \pm 0,00$ & $0,00 \pm 0,00$ & $0,00 \pm 0,00$ \\
\hline
\end{tabular}

\begin{tabular}{lcc}
\hline Período 7 & Teste de Kruskal-Wallis & \\
$\mathrm{H}_{\text {calculado }}=0$ & $\left(\mathrm{H}_{\text {critico }}=5,71\right)$ & $\mathrm{A}=\mathrm{C}=\mathrm{S}$
\end{tabular}

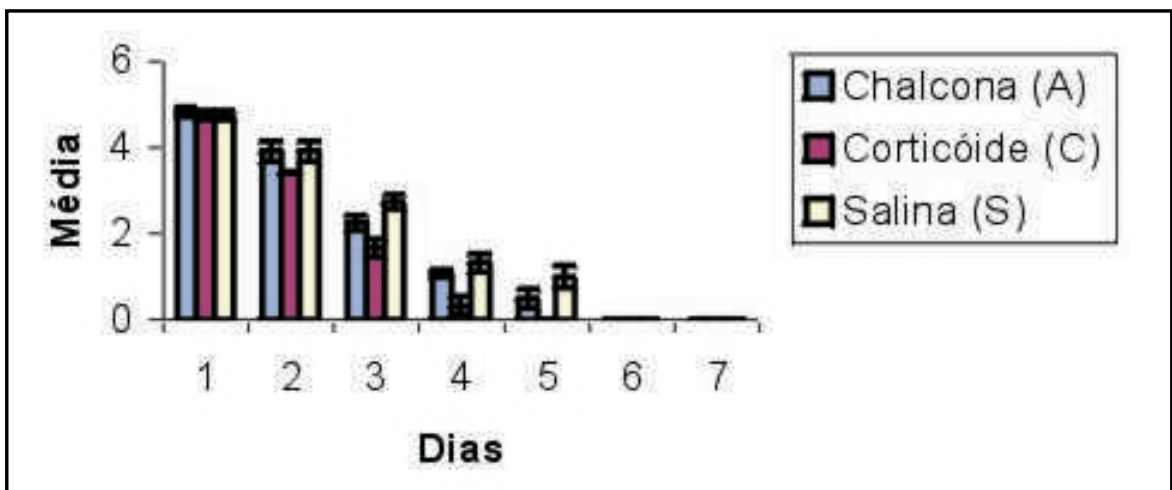

FIGURA 3 - Média \pm E. P. M. de escores da avaliação clínica observados até o dia 7 da indução da conjuntivite alérgica em cobaias e tratada com chalcona, corticóide e salina.

fície corneana aos 40 minutos. Com 7 horas de observação, evidenciou-se hiperemia conjuntival, acentuada quemose, intenso lacrimejamento, fotofobia, edema e hiperemia palpebral e fluido lacrimal turvo. Com 24 horas notou-se exacerbação do quadro com descarga purulenta na superfície ocular, pannus, opacificação e úlcera de córnea. Após 48 horas, houve redução gradativa dos achados descritos de modo que com 7 dias após a indução da conjuntivite, todas essas alterações desapareceram espontaneamente. Os resultados da avaliação clínica foram semelhantes aos descritos em estudos anteriores ${ }^{(3,4)}$.

Percebeu-se uma melhora clínica do quadro inflamatório nos grupos chalcona e corticóide quando comparado ao controle.
O grupo corticóide apresentou melhora clínica da inflamação quando comparado ao grupo chalcona. No sétimo dia da indução, todos os grupos tratados não apresentaram alterações clínicas. Apesar da involução clínica espontânea do processo alérgico após 7 dias da indução, o tratamento com chalcona ou corticóide antecipou a cura clínica que justifica a procura por novas formas de tratamento para essa afecção.

O estudo morfológico da córnea do OD sugeriu que a chalcona e o corticóide, no período 3, apresentaram efeitos terapêuticos semelhantes sobre a exocitose. A presença de células inflamatórias acima da membrana basal, dentro do espaço epitelial, é anormal e significa inflamação ativa. Em condições normais, essas células não são encontradas no epitélio, portanto a exocitose constitui um importante parâmetro para quantificar a inflamação. Mesmo sem apresentar diferenças significantes entre os grupos tratados, o edema, a necrose e a vascularização estiveram presentes na córnea do OD caracterizando o acometimento por essa afecção mesmo que em menor intensidade quando comparado à conjuntiva.

À análise morfológica da conjuntiva do OD evidenciou-se diferenças significantes dos parâmetros entre os grupos estudados. Observou-se que a chacona e o corticóide apresentaram efeitos terapêuticos semelhantes sobre a exocitose, edema, necrose e vascularização. Isso comprova o efeito antiinflamatório da chalcona já estudado em pesquisas anteriores ${ }^{(12-13)}$.

Embora a avaliação clínica seja considerada um importante critério de avaliação, o estudo morfológico demonstra ser mais fidedigno. Mesmo após a cura clínica com 7 dias da indução da conjuntivite alérgica, ainda persistiam alterações morfológicas entre os grupos estudados.

O modelo experimental de conjuntivite alérgica induzida por ovalbumina em cobaias foi reproduzido por diversos pesquisadores com a finalidade de estudar os efeitos de antihistamínicos, esteróides, cromoglicato de sódio, lodoxamida, $\mathrm{N}$ acetil aspartilglutamato de sódio, benzodiazepínicos, nedocromil, indometacina, ciclosporina e aspirina ${ }^{(5-11)}$.

Não há relatos do uso da aroeira-do-sertão em conjuntivite alérgica induzida por 
TABELA 4 - Média \pm E. P. M. dos escores da análise morfológica verificados na córnea OD nos dias 1,3 e 7 da indução da conjuntivite alérgica em cobaias e tratada com chalcona, corticóide e salina

\begin{tabular}{|c|c|c|c|c|c|c|c|c|c|}
\hline \multicolumn{10}{|c|}{ Análise morfológica córnea OD (Média \pm E. P. M.) } \\
\hline \multirow[b]{2}{*}{ Dias } & \multicolumn{3}{|c|}{ Chalcona } & \multicolumn{3}{|c|}{ Corticóide } & \multicolumn{3}{|c|}{ Salina } \\
\hline & 1 & 3 & 7 & 1 & 3 & 7 & 1 & 3 & 7 \\
\hline \multirow[t]{2}{*}{ Exocitose } & 2,83 & $\pm 0,17$ & 0,00 & 2,83 & 0,17 & 0,17 & 2,83 & 1,00 & 0,00 \\
\hline & $\pm 0,17$ & 0,17 & $\pm 0,00$ & $\pm 0,17$ & $\pm 0,17$ & $\pm 0,17$ & $\pm 0,17$ & $\pm 0,00$ & $\pm 0,00$ \\
\hline \multirow[t]{2}{*}{ Edema } & 2,33 & 0,50 & 0,00 & 2,33 & 0,67 & 0,00 & 2,33 & 1,00 & 0,33 \\
\hline & $\pm 0,21$ & $\pm 0,22$ & $\pm 0,00$ & $\pm 0,21$ & $\pm 0,21$ & $\pm 0,00$ & $\pm 0,21$ & $\pm 0,00$ & $\pm 0,21$ \\
\hline \multirow[t]{2}{*}{ Necrose } & 1,50 & 0,00 & 0,00 & 1,50 & 0,00 & 0,00 & 1,50 & 0,00 & 0,00 \\
\hline & $\pm 0,22$ & 0,00 & $\pm 0,00$ & $\pm 0,22$ & $\pm 0,00$ & $\pm 0,00$ & $\pm 0,22$ & $\pm 0,00$ & $\pm 0,00$ \\
\hline \multirow[t]{2}{*}{ Vasos } & 2,50 & 1,00 & 0,00 & 2,50 & 1,00 & 1,00 & 2,50 & 1,00 & 1,00 \\
\hline & $\pm 0,34$ & $\pm 0,00$ & $\pm 0,00$ & 0,34 & $\pm 0,00$ & $\pm 0,00$ & $\pm 0,34$ & $\pm 0,00$ & $\pm 0,00$ \\
\hline
\end{tabular}

(Teste de Kruskal-Wallis)

$$
\left(\mathrm{H}_{\text {critico }}=5,71\right)
$$

TABELA 5 - Média \pm E. P. M. dos escores da análise morfológica verificados na conjuntiva OD nos dias 1,3 e 7 da indução da conjuntivite alérgica em cobaias e tratada com chalcona, corticóide e salina

\begin{tabular}{cccccccccc}
\hline \multicolumn{1}{c}{ Análise morfológica córnea OD (Média \pm E. P. M. ) } \\
\hline Dias & 1 & 3 & 7 & 1 & 3 & 7 & 1 & 3 & 7 \\
\hline Exocitose & 2,83 & 1,00 & 0,00 & 2,83 & 0,67 & 0,33 & 2,83 & 1,67 & 0,83 \\
& $\pm 0,17$ & $\pm 0,26$ & $\pm 0,00$ & $\pm 0,17$ & $\pm 0,21$ & $\pm 0,21$ & $\pm 0,17$ & $\pm 0,21$ & $\pm 0,17$ \\
Edema & 2,67 & 0,67 & 0,00 & 2,67 & 1,00 & 0,17 & 2,67 & 1,67 & 0,67 \\
& $\pm 0,33$ & $\pm 0,21$ & $\pm 0,00$ & $\pm 0,33$ & $\pm 0,00$ & $\pm 0,17$ & $\pm 0,33$ & $\pm 0,21$ & $\pm 0,21$ \\
Necrose & 2,17 & 0,00 & 0,00 & 2,17 & 0,00 & 0,00 & 2,17 & 0,83 & 0,00 \\
& $\pm 0,17$ & $\pm 0,00$ & $\pm 0,00$ & $\pm 0,17$ & $\pm 0,00$ & $\pm 0,00$ & $\pm 0,17$ & $\pm 0,17$ & $\pm 0,00$ \\
& 2,83 & 1,00 & 1,00 & 2,83 & 1,00 & 1,00 & 2,83 & 1,00 & 1,00 \\
Vasos & $\pm 0,17$ & $\pm 0,00$ & $\pm 0,00$ & $\pm 0,17$ & $\pm 0,00$ & $\pm 0,00$ & $\pm 0,17$ & $\pm 0,42$ & $\pm 0,00$ \\
\hline
\end{tabular}

Teste de Kruskal-Wallis

$$
\left(\mathrm{H}_{\text {critico }}=5,71\right)
$$

ovalbumina em cobaias. Sabe-se do seu uso popular nas mais diversas áreas da medicina pelo seu efeito antiinflamatório (12-13).

No presente trabalho, as avaliações clínicas e morfológicas tornaram evidentes que a chalcona teve efeito antiinflamatório e anti-alérgico semelhante ao corticóide na conjuntivite alérgica induzida por ovalbumina em cobaias. Esse fato gera perspectivas para o aproveitamento dessa planta como fitoterápico. No entanto, novos estudos deverão ser realizados, utilizando esse e outros modelos de conjuntivite alérgica, no sentido de confirmar as atividades antiinflamatórias e anti-alérgicas aqui encontradas. Uma vez confirmadas essas atividades, seria importante pesquisar sua ação em outras afecções oculares.

\section{Conclusão}

A chalcona tem efeito terapêutico semelhante ao corticóide na conjuntivite alérgica induzida por ovalbumina, em cobaias.

\section{Referências}

1. Sousa LB, Freitas D. Alergia ocular. Atualidades 2001;1:1-9.

2. Samra Z, Zavaro A, Barishak $Y$, Sompolinsky D. Vernal keratocon- junctivitis: The significance of immunoglobulin E levels in tears and serum. Int. Archs Allergy Appl Immun 1984;74:158-64.

3. Freitas D, Belfort Jr R. Conjuntivites. Arq Bras Oftalm 1992;55(5):196-205.

4. Sompolinsky D, Lundberg L, Prause U. Immunologically induced purulent anterior segment inflammation of the guinea pig eye. Allergy 1992;47:234-42.

5. Nitzan Y, Boldur I, Afgin Y, Barishak YR, Malik Z, Sompolinsky D. The dynamics of inflammation of anterior eye in a novel experimental model for hypersensitivity. Cytobios 1996;88:105-17.

6. Hoyos L, Norris A, Vargaftig BB. Effects of nedocromil sodium on antigen-induced conjunctivitis in guinea pigs. Adv Ther 2000;17(1): 1-6. 
7. Gupta S, Khurana A, Ahluwealia B, Gupta N. Topical indomethacin for vernal keratoconjunctivitis. Acta Ophthalmol 1991;69:95.

8. Abelson M, Butrus S, Weston J. Aspirin therapy in vernal conjunctivitis. Am J Ophthalmol 1983; 95:502.

9. Kawata E, Mori J, Ishizaki M. Effect of benzodiazepine on antigen-induced eosinophil infiltration into guinea pig conjunctiva. Arerugi 1996;45(5):478-84.

10. Dwyer Rsc, Darougar S, Jones BR. Immediate hypersensitivy in the guinea pig conjunctiva. II effect or treatment with antihistamines, steroids and disodium cromoglycate. Mod Probl Ophthal 1976; 16:186-95.

11. Goldschmith P, Luyckx J. Effects of lodoxamide, dissodium cromoglicate and $\mathrm{N}$ acetyl-aspartyl-glutamate sodium salt on ocular active anaphylaxis. Allerg Immunol 1996; 28(4):124-6.

12. Rodrigues, LV. Análise morfológica morfométrica da colite induzida por ácido acético, em ratos, e tratada com extratos vegetais (Myracrodruon urundeuva $\mathrm{Fr}$. All.) [Tese - Doutorado]. Universidade Federal de São Paulo - Escola Paulista de Medicina; 1999.

13. Viana GSB, Matos FJA, Bandeira MAM, Rao VSN. Chalcona-do-Sertão (Myracrodruon urundeuva Fr. All.): estudo botânico, farmacognóstico, químico e farmacológico. Fortaleza:UFC;1995.

14. Brasil. Lei Federal n. 6.638, de 8 de maio de 1979. Estabelece normas para a prática didático-científica da vivissecção de animais e determina outras providências. In Brasil. Coleção deleis de 1979: atos legislativos do poder executivo. Leis de abril a junho. Brasília, Departamento de Imprensa nacional, 1979. p 33-4.

15. Dwyer RSTC, Turk JL, Darougar S. Immediate hypersensitivity in the guinea pig conjunctiva. I. Characterization of the IgE e IgG1 antibodies involved. Int. Archs Allergy ppl Immunol 1974;46:910-24.

\begin{abstract}
Mendonça ARJ, Rodrigues LV, Viana GSB. Clinical and morphologic analysis of allergic conjunctivitis induced by ovalbumin and treated with chalcona in guinea pigs. Acta Cir Bras [serial online] 2004 Jan-Feb;19(1). Available from URL: http://www.scielo.br/acb.

ABSTRACT - Purpose: To study for clinical and morphological point of views, the effects of a chalcone in allergic conjunctivitis induced by ovalbumim in guinea pig. Methods: Fifty-four white male guinea pigs weighing approximately $400 \mathrm{~g}$ were used in the study. All animals were sensitized by intraperitoneal injection of ovalbumin suspended in Freund's complete adjuvant solution. Conjunctivitis was induced by the ovalbumin by instillation of ovalbumin in conjunctival sac of right eye's. The animals were randomized in 3 groups agreement with the proposed treatment: chalcone,corticoid and saline. The clinical analysis were recorded at 5, 10 e $40 \mathrm{~min}, 7$ e $24 \mathrm{~h}$ after induced and daily until 7 days after induced. Morphologic analysis consisted in evaluating edema, necrosis, vascularization and exocytosis at the 1, 3 and 7 days following induction of conjunctivitis. Results: Clinical alterations were more accentuated $24 \mathrm{~h}$ after induction. Inflammatory signs were less apparent in chalcone group as compared to saline Corticoid group presented less inflammatory signs when compared to chalcone and control groups. Morphologic analysis disclosed that chalcona effect is similar to corticoid effects. Conclusion: It is concluded that chalcona had therapeutic effect in the allergic conjunctivitis induced by ovalbumine in guinea pigs.
\end{abstract}

KEY WORDS - Allergy conjunctivitis. Ovalbumin. Chalcone. Guinea pig.

Conflito de interesse: nenhum

Correspondência:

Fonte de financiamento: nenhuma

Lusmar Veras Rodrigues

Rua Arthur Façanha, 75/1702

60175-130 Fortaleza - Ceará

Tel: (85)263-2743

Fax: (85)263-3465

lusmarveras@aol.com

Data do recebimento: 15/12/2003

Data da revisão: 04/01/2004

Data da aprovação: 21/01/2004

Fotos coloridas disponíveis em www.scielo.br/acb 